\title{
Comment on "Should COVID-19 Concern Nephrologists? Why and to What Extent? The Emerging Impasse of Angiotensin Blockade"
}

\author{
Erkan Cure $^{a}$ Medine Cumhur Cure ${ }^{b}$

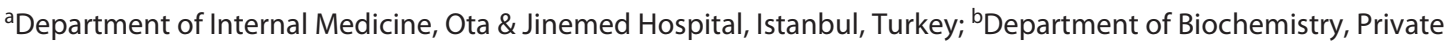 \\ Practice, Istanbul, Turkey
}

Dear Editor,

We read with great interest the review article by Perico et al. [1] "Should COVID-19 Concern Nephrologists? Why and to What Extent? The Emerging Impasse of Angiotensin Blockade." The authors hypothesized that angiotensin receptor antagonists (ARBs) can prevent the entry of the novel coronavirus into the cell by changing the structure of angiotensin-converting enzyme 2 (ACE2). In addition, they said that $A R B s$ may protect against acute respiratory distress syndrome (ARDS) by increasing the angiotensin 1-7 level. We think ARBs may exacerbate the 2019 novel coronavirus disease (COVID-19) infection by increasing the ACE2 level. We would like to point out that ARBs should be discontinued in COVID-19 infection.

ARBs increase the circulating angiotensin II level. Angiotensin II may increase pulmonary vascular leakage, causing lung injury during COVID-19 infection. The authors claimed that ARBs could alter the ACE2 structure [1]. However, according to the current literature, there is no information that ARBs change the structure of ACE2. ACE2 is present in the lungs, brain, heart, kidneys, and vessels. ARBs increase the ACE2 level in the brain and heart. There is no scientific data yet that $A R B s$ increase the ACE2 level in lung tissue [2]. The novel coronavirus passes into the cell using ACE2 as a

karger@karger.com

(C) 2020 S. Karger AG, Basel

www.karger.com/nef

Karger host and causes infection. The increase in the ACE2 level by ARBs may increase the viral load entering the cell in the brain and heart. Increased virus entry into the cell can lead to disease exacerbation. The virus causes myocarditis, myocardial edema, and myocardial injury by making cardiac involvement. A previous study reported that in patients with cardiac damage, mortality was more than 10 times higher than in those without cardiac damage [3]. In addition, COVID-19 was detected in the cerebrospinal fluid. There are ACE2 receptors in the rostral ventrolateral medulla in the brain. ACE2 converts angiotensin II to angiotensin 1-7. Angiotensin 1-7 has anti-inflammatory and vasodilatory effects on many tissues. However, an increase in the angiotensin 1-7 level in the brain activates the sympathetic nervous system, increasing arterial blood pressure [4]. Activation of the neurogenic sympathetic system leads to systemic vasoconstriction [5]. Thus, raised sympathetic activity leads to myocardial injury and ARDS by pulmonary capillary leakage. On the other hand, it has been reported in a limited number of animal studies that angiotensin 1-7 intravenous or intraperitoneal administration is useful in ARDS treatment [1]. We speculate that ARBs may be dangerous as it increases the ACE2 level in the brain and heart tissue. 


\section{Acknowledgements}

We thank Luca Perico et al. [1] for drawing attention to this important issue.

\section{Disclosure Statement}

The authors have no conflicts of interest to declare.

\section{References}

1 Perico L, Benigni A, Remuzzi G. Should COVID-19 concern nephrologists? Why and to what extent? The emerging impasse of angiotensin blockade. Nephron. 2020. doi:10.1159/ 000507305.

2 Patel AB, Verma A. COVID-19 and angiotensin-converting enzyme inhibitors and angiotensin receptor blockers: what is the evidence?. JAMA. 2020. doi:10.1001/jama. 2020.4812.

3 Shi S, Qin M, Shen B, Cai Y, Liu T, Yang F, et al. Association of cardiac injury with mortal- ity in hospitalized patients with COVID-19 in Wuhan, China. JAMA Cardiol. 2020. doi: 10.1001/jamacardio.2020.0950.

4 Bilodeau MS, Leiter JC. Angiotensin 1-7 in the rostro-ventrolateral medulla increases blood pressure and splanchnic sympathetic nerve activity in anesthetized rats. Respir Physiol Neurobiol. 2018 Jan;247:103-11.

5 Al-Dhahir MA, Das Joe M, Sharma S. Neurogenic pulmonary edema copyright (c) 2020 . Tampa/St. Petersburg: StatPearls Publishing LLC; 2020 